\title{
The proliferative effects of asbestos-exposed peripheral blood mononuclear cells on mesothelial cells
}

\author{
YUHO MAKI $^{1}$, YASUMITSU NISHIMURA ${ }^{2}$, SHINICHI TOYOOKA $^{1}$, JUNICHI SOH ${ }^{1}$, KAZUNORI TSUKUDA ${ }^{1}$, \\ KAZUHIKO SHIEN $^{1}$, MASASHI FURUKAWA ${ }^{1}$, TAKAYUKI MURAOKA ${ }^{1}$, TSUYOSHI UENO ${ }^{1}$, \\ NORIMITSU TANAKA ${ }^{1}$, HIROMASA YAMAMOTO ${ }^{1}$, HIROAKI ASANO ${ }^{1}$, MEGUMI MAEDA ${ }^{2}$, \\ NAOKO KUMAGAI-TAKEI ${ }^{2}$, SUNI LEE ${ }^{2}$, HIDENORI MATSUZAKI ${ }^{2}$, \\ TAKEMI OTSUKI ${ }^{2}$ and SHINICHIRO MIYOSHI ${ }^{1}$ \\ ${ }^{1}$ Department of General Thoracic Surgery, \\ Okayama University Graduate School of Medicine, Dentistry and Pharmaceutical Sciences, Okayama 700-8558; \\ ${ }^{2}$ Department of Hygiene, Kawasaki Medical School, Kurashiki, Okayama 701-0192, Japan
}

Received December 18, 2014; Accepted January 21, 2016

DOI: $10.3892 / \mathrm{ol} .2016 .4412$

\begin{abstract}
Malignant mesothelioma (MM) is thought to arise from the direct effect of asbestos on mesothelial cells. However, MM takes a long time to develop following exposure to asbestos, which suggests that the effects of asbestos are complex. The present study examined the effects of asbestos exposure on the cell growth of MeT-5A human mesothelial cells via cytokines produced by immune cells. Peripheral blood mononuclear cells (PBMCs) were stimulated with antibodies against cluster of differentiation (CD)3 and CD28 upon exposure to the asbestos chrysotile A (CA) or crocidolite (CR); the growth of MeT-5A cells in media supplemented with PBMC culture supernatants was subsequently examined. MeT-5A cells exhibited an increase in proliferation when grown in supernatant from the 7-day PBMC culture exposed to $\mathrm{CA}$ or $\mathrm{CR}$. Analysis of cytokine production demonstrated increased levels of granulocyte colony-stimulating factor (G-CSF), granulocyte-macrophage colony-stimulating factor (GM-CSF), interleukin (IL)-1 $\alpha$, IL-1 $\beta$, IL-3, IL-5, IL-13 and IL-17A in supernatants. Individual administration of these cytokines, excluding G-CSF and GM-CSF, led to an increase in cell growth of MeT-5A, whereas this effect was not observed following the combined administration of these cytokines. The results indicate that cytokines secreted by immune cells upon exposure to asbestos cause an increase in the growth activity of mesothelial cells, suggesting that alterations in the production of cytokines by immune cells may contribute to tumorigenesis in individuals exposed to asbestos.
\end{abstract}

Correspondence to: Dr Yasumitsu Nishimura, Department of Hygiene, Kawasaki Medical School, 577 Matsushima, Kurashiki, Okayama 701-0192, Japan

E-mail: yas@med.kawasaki-m.ac.jp

Key words: asbestos, mesothelial cells, mesothelioma, peripheral blood mononuclear cells, T-cell, $\mathrm{T}_{\mathrm{h}} 2$ cytokines

\section{Introduction}

Malignant mesothelioma (MM) is an aggressive tumor with a poor prognosis; asbestos (e.g., chrysotile, crocidolite or amosite) exposure is indisputably a major factor in the development of this tumor (1). Asbestos is the generic name for a group of silicate minerals (complexes containing metals, such as iron and magnesium) and is categorized as a Group I carcinogen by the International Agency for Research on Cancer (2). The accumulation of DNA damage due to asbestos-induced production of reactive oxygen/nitrogen species is considered to be one of the predominant mechanisms underlying the development of MM (3). However, MM is typically observed to develop a long time after asbestos exposure (4), which suggests that the effects of asbestos are complex, and leads to the hypothesis that immunological abnormalities may be associated with the development of MM.

Previously, our group reported that the T cell line MT-2, when continuously exposed to asbestos, exhibited resistance to apoptosis, indicating that asbestos could enhance the survival of cluster of differentiation $(\mathrm{CD}) 4^{+} \mathrm{CD} 25^{+}$regulatory $\mathrm{T}$ ce11s (5-7). In addition, human natural killer cells exposed to asbestos exhibited decreased cytotoxicity and altered expression of activating receptors in vitro (6). Most recently, we reported that asbestos exposure suppressed the induction of cytotoxic $\mathrm{T}$ lymphocytes during a mixed lymphocyte reaction (8). These findings indicate that asbestos exposure has the potential to influence immune responses, which may be associated with the pathogenesis of MM following exposure to asbestos.

Consideration of the relationship between alteration of immune responses and pathogenesis of mesothelioma may indicate that asbestos exposure has the potential to cause impairment of tumor immunity; transformed cells may be able to escape tumor immunity and develop MM (5,9-11). Alternatively, altered production of cytokines by immune cells upon exposure to asbestos is another potential mechanism that may contribute to the pathogenesis of mesothelioma. 
It is possible that cytokines produced by immune cells existing in or migrating into the pleural cavity, or cytokines transported through the blood stream following their production in lymphoid organs, may affect the function of pleural cells (11-15). Previous studies have reported high serum levels of granulocyte colony-stimulating factor (G-CSF), transforming growth factor $\beta$, interleukin (IL)-6 and IL-10 in patients with mesothelioma (16-18). However, it is still unknown whether cytokines derived from immunocompetent cells exposed to asbestos influence normal mesothelial cells.

Therefore, in the current study, peripheral blood mononuclear cells (PBMCs) from healthy donors were directly exposed to asbestos under stimulation with antibodies against CD3 and CD28, and the effects of the resulting culture supernatants on the cell growth of mesothelial cells were examined in vitro. The aforementioned antibodies were utilized to stimulate $\mathrm{T}$ lymphocytes in the PBMC cultures, due to the well-known production of various kinds of cytokines by these cells to control immune responses (19). The concentrations of various cytokines in the culture supernatants were subsequently assayed. Finally, the cell growth of mesothelial cells in media supplemented with the cytokines that had been found to increase in the supernatants of PBMC cultures under exposure to asbestos was examined.

\section{Materials and methods}

In vitro exposure of PBMCs to asbestos and stimulation with antibodies to CD3 and CD28. PBMCs were collected using the Ficoll-Hypaque density gradient method from $20 \mathrm{ml}$ of heparinized blood from three healthy donors, as reported previously (20). The present study was approved by the Ethics Committee of Kawasaki Medical School (Kurashiki, Japan; approval no., 883-2). Tissue culture plates (96-well; AGC Techno Glass, Shizuoka, Japan) were coated overnight with $100 \mu \mathrm{l}$ of anti-CD3 (monoclonal mouse anti-human; catalog no., IM1304; Beckman-Coulter, Fullerton, CA, USA) diluted with phosphate-buffered saline to a concentration of $0.5 \mu \mathrm{g} / \mathrm{ml}$. The PBMCs ( $1 \times 10^{5}$ cells per well) were then cultured in $200 \mu \mathrm{l}$ of medium containing 0,5 or $20 \mu \mathrm{g} / \mathrm{ml}$ of chrysotile A (CA) or crocidolite (CR). CA and CR were provided by the Department of Occupational Hygiene, National Institute for Occupational Health (Johannesburg, South Africa). Each medium contained $0.5 \mu \mathrm{g} / \mathrm{ml}$ of anti-CD28 (monoclonal mouse anti-human; catalog no., IM1376; Beckman-Coulter). The basic medium was RPMI-1640 medium (Sigma-Aldrich, St. Louis, MO, USA) supplemented with $10 \%$ fetal bovine serum (Sigma-Aldrich), and the antibiotics streptomycin and penicillin (Meiji Seika Pharma Co., Ltd., Tokyo, Japan). After 2 and 7 days of incubation in a humidified atmosphere of 5\% $\mathrm{CO}_{2}$ at $37^{\circ} \mathrm{C}$, the cells and supernatants were harvested, and the supernatants were separated from the cells and asbestos by centrifugation for $10 \mathrm{~min}$ at $1710 \mathrm{x} \mathrm{g}$. These supernatants were divided into aliquots and stored at $-20^{\circ} \mathrm{C}$ prior to use.

Cell culture. The non-malignant simian virus 40-transformed human pleural mesothelial cell line MeT-5A was obtained from the biological resource center of the American Type Culture Collection (Manassas, VA, USA) through the distributor in Japan (Summit Pharmaceuticals International, Tokyo, Japan).
MeT-5A cells were cultured on Falcon ${ }^{\mathrm{TM}} 10-\mathrm{cm}$ plates (Thermo Fisher Scientific, Carlsbad, CA, USA). The basic medium and culture conditions were the same as those used for the culture of PBMCs.

Measurement of cytokines. A total of 26 different cytokines and chemokines were assayed simultaneously in the supernatants of the cultured PBMCs using a Milliplex MAP Human Cytokine/Chemokine Pre-mixed 26 Plex Panel (catalog no., MPXHCYTO60KPMX26; EMD Millipore, Billerica, MA, USA) according to the manufacturer's instructions. This kit is designed to assay concentrations of IL- $1 \alpha$, IL- $1 \beta$, IL-2, IL-3, IL-4, IL-5, IL-6, IL-7, IL-8, IL-10, IL-12p40, IL-12p70, IL-13, IL-15, IL-17A, Eotaxin, G-CSF, GM-CSF, intereron (IFN)- $\alpha 2$, IFN- $\gamma$, IFN $\gamma$-induced protein 10 , monocyte chemotactic protein 1 , macrophage inflammatory protein (MIP)-1 $\alpha$, MIP-1 $\beta$, tumor necrosis factor (TNF)- $\alpha$ and TNF- $\beta$. Fluorescence-labeled beads were incubated with the supernatants at $4^{\circ} \mathrm{C}$ overnight, and then washed with detection antibodies at room temperature for an hour followed by incubation with streptavidin-phycoerythrin. Finally, the fluorescence intensity of the beads was measured and analyzed for the concentration of cytokines and chemokines using the Luminex $200^{\mathrm{TM}}$ xPONENT System version 3.1 (EMD Millipore). Relative values of the cytokines were obtained by dividing each value by the average of the values obtained for each cytokines.

Assay of cell proliferation. MeT-5A cells were plated at a density of $3 \times 10^{5}$ cells per $10-\mathrm{cm}$ dish and cultured $72 \mathrm{~h}$ prior to the following experiments. The cells were then cultured in 96-well tissue culture plates $\left(6 \times 10^{3}\right.$ cells per well) in $100 \mu 1$ of medium containing $12.5 \mu \mathrm{l}$ of the supernatant collected from the PBMC culture. After $48 \mathrm{~h}$ of culture, the growth properties were analyzed using a water-soluble tetrazolium salt (WST-1) assay, as described previously (21). MeT-5A cells were also treated with the following recombinant cytokines: G-CSF (1.0 ng/ml; catalog no., 561701; BioLegend, San Diego, CA, USA), GM-CSF (10 ng/ml; catalog no., 572902), IL-1 $\alpha$ (2.5 ng/ml; catalog no., 570002), IL-1 $\beta$ (2.5 ng/ml; catalog no., 579402$)$, IL-3 (1.0 ng/ml; catalog no., 560503), IL-5 (1.0 ng/ml; catalog no., 560701), IL-13 (5.0 ng/ml; catalog no., 571102) and IL-17A (50 ng/ml; catalog no., 570502) for $48 \mathrm{~h}$; the concentrations of cytokines were determined according to the supernatant of PBMCs. The WST-1 assay was then performed using the same protocol. Optical density at $450 \mathrm{~nm}$ (OD450 nm) was measured and normalized to a standard condition, which was the OD450 nm without supernatants or cytokines.

Statistical analysis. Statistical analysis was performed using GraphPad Prism version 6.07 software (GraphPad Software, Inc., La Jolla, CA, USA). Values are expressed as the mean \pm standard deviation. For cytokine measurements, data were analyzed using an unpaired $t$-test and differences were considered significant at $\mathrm{P}<0.01$ compared to the control. For the WST-1 test, differences among experimental groups were determined using Kruskal-Wallis one-way analysis of variance followed by a Dunn multiple comparisons post-hoc test. Differences were considered significant at $\mathrm{P}<0.01$. 
A

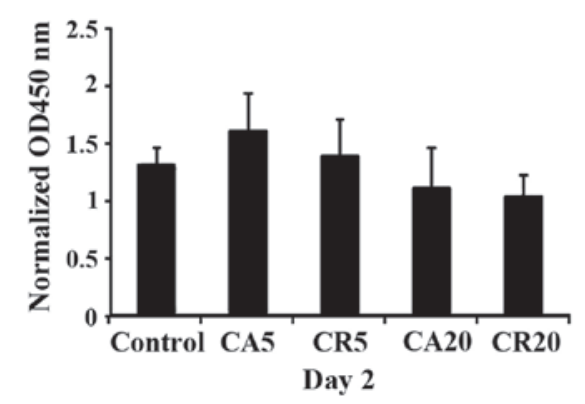

B

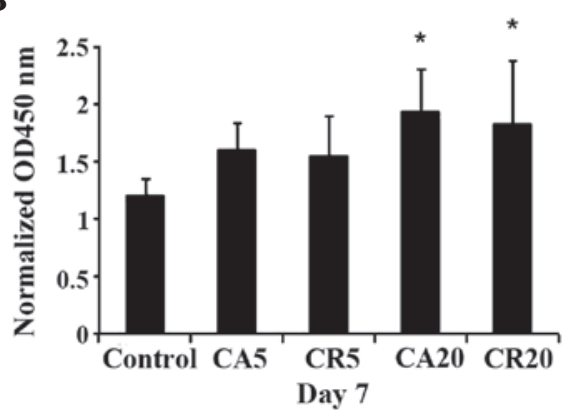

Figure 1. The effects of supernatants from PBMC cultures with asbestos on cell growth of human mesothelial cells. MeT-5A human mesothelial cells were cultured in media supplemented with supernatants from PBMC cultures: PBMCs were cultured with 5 or $20 \mu \mathrm{g} / \mathrm{ml}$ of CA or CR upon stimulation with antibodies against CD3 and CD28 for (A) 2 or (B) 7 days, and culture supernatants were harvested and used for MeT-5A cultures. Cell growth was evaluated using water-soluble tetrazolium salt assays. Values are expressed as the mean \pm standard deviation. Statistical significance is expressed as * $\mathrm{P}<0.01$ vs. controls. PBMC, peripheral blood mononuclear cells; CA, chrysotile A; CR, crocidolite; CD, cluster of differentiation; CA5, $5 \mu \mathrm{g} / \mathrm{ml}$ CA; CR5, $5 \mu \mathrm{g} / \mathrm{ml}$ CR; CA20, $20 \mu \mathrm{g} / \mathrm{ml}, \mathrm{CA}$; CR20, $20 \mu \mathrm{g} / \mathrm{ml} \mathrm{CR}$; OD450 nm, optical density at $450 \mathrm{~nm}$.

\section{Results}

Cell growth is enhanced in mesothelial cells exposed to supernatants from asbestos-exposed PBMCs. To evaluate the cell growth of mesothelial cells as affected by PBMC supernatants, MeT-5A cells were cultured in media supplemented with supernatant collected from PBMCs that had been cultured for 2 or 7 days with $5 \mu \mathrm{g} / \mathrm{ml} \mathrm{CA}$ or CR (CA5 and CR5) and $20 \mu \mathrm{g}$ CA or CR (CA20 and CR20) under stimulation with anti-CD3 and anti-CD28 antibodies. MeT-5A cells were assayed for cell growth. PBMC supernatant without asbestos was used as the control. In the 2-day group, growth was not significantly enhanced compared with the control group, although a marginal increase in growth was observed in the group exposed to the $5 \mu \mathrm{g} / \mathrm{ml}$ CA culture supernatant (OD450 nm: Control, 1.357 \pm 0.304 ; CA5, $1.750 \pm 0.401, \mathrm{P}=0.033$; CR5 1.579 \pm 0.536 , $\mathrm{P}>0.999$; CA20, 1.132 $\pm 0.208, \mathrm{P}=0.184$; CR20, $1.066 \pm 0.169$, $\mathrm{P}=0.043)$. In the 7-day group, the MeT-5A cells exposed to supernatants from PBMC cultures with $20 \mu \mathrm{g} / \mathrm{ml}$ of CA or CR exhibited significantly enhanced proliferation; MeT-5A cells exposed to supernatants from cultures with $5 \mu \mathrm{g} / \mathrm{ml}$ of CA or CR exhibited a slight, non-significant tendency for increased proliferation (Fig. 1) (OD450 nm: Control 1.219 \pm 0.216 ; CA5, 1.665 $\pm 0.344, \mathrm{P}=0.026$; CR5, $1.583 \pm 0.331, \mathrm{P}=0.028$; CA20, $2.085 \pm 0.586, \mathrm{P}<0.0001 ; \mathrm{CR} 20,1.908 \pm 0.632, \mathrm{P}<0.0001)$. The difference in the effects on MeT-5A cells between culture supernatants of 5 and $20 \mu \mathrm{g} / \mathrm{ml}$ asbestos doses were also compared. Supernatants from cultures with $5 \mu \mathrm{g} / \mathrm{ml}$ of CA or CR were associated with a tendency for enhanced proliferation of MeT-5A cells compared with supernatants of $20 \mu \mathrm{g} / \mathrm{ml}$ in the 2-day group ( $\mathrm{P}=0.001$ and $\mathrm{P}=0.07$, respectively). By contrast, there was no significant difference in cell proliferation between $5 \mu \mathrm{g} / \mathrm{ml}$ and $20 \mu \mathrm{g} / \mathrm{ml}$ doses in the 7-day group. Additionally, there were no significant differences between the effects of $\mathrm{CA}$ and $\mathrm{CR}$ when comparing equivalent doses and durations of treatment. These results indicate that cell growth of mesothelial cells is enhanced by secretory factors derived from PBMCs exposed to asbestos, and that the factors produced later during the PBMC cultures are more effective than those produced in the earlier stages.

Profile of cytokines in supernatants of PBMC cultures with asbestos. The aforementioned results indicated the existence of certain factors in supernatants that enhance the cell growth of mesothelial cells. Therefore, the concentrations of various cytokines and chemokines in the supernatants of PBMC cultures were examined using Luminex technology. Among the 26 cytokines assayed, the concentrations of 8 cytokines, comprising G-CSF, GM-CSF, IL-1 $\alpha$, IL- $1 \beta$, IL-3, IL-5, IL-13 and IL-17A, were significantly higher in PBMC supernatants cultured with asbestos than in control supernatants (Table I; Fig. 2); the kinetics of these cytokine productions were dependent on the dose and type of asbestos, as well as the duration of the culture period. IL1- $\alpha$ and IL-1 $\beta$ increased in the 2- and 7-day groups, in which CA exposure was more effective in increasing concentrations than CR. The concentrations of 6 cytokines were higher in the 7-day group compared with the 2-day group: IL-3, IL-5, IL-13 and IL-17A increased significantly following exposure to $20 \mu \mathrm{g} / \mathrm{ml}$ of CA or CR for 7 days, with both types of asbestos exposure producing a dose-dependent increase in the production of cytokines (Fig. 2). The concentration of GM-CSF increased following exposure to $5 \mu \mathrm{g} / \mathrm{ml}$ of CA or CR, and $20 \mu \mathrm{g} / \mathrm{ml}$ of CA $(\mathrm{P}<0.001, \mathrm{P}=0.006$ and $\mathrm{P}=0.006$, respectively); however, exposure to $20 \mu \mathrm{g} / \mathrm{ml}$ of CR had no significant effect. Furthermore, there were significant increases in G-CSF in response to cultures with 5 or $20 \mu \mathrm{g} / \mathrm{ml}$ of CA and $5 \mu \mathrm{g} / \mathrm{ml}$ of CR. These results indicate that asbestos exposure may lead to increases in G-CSF, GM-CSF, IL-1 $\alpha$, IL-1 $\beta$, IL-3, IL-5, IL-13 and IL-17A production by PBMCs upon T-cell stimulation. Notably, the majority of the increases occurred at a later time during the culture period.

Cell growth of mesothelial cells in the presence of cytokines. To screen the effect of these cytokines on the cell growth of mesothelial cells, MeT-5A cells were cultured in media supplemented with recombinant G-CSF, GM-CSF, IL- $1 \alpha$, IL-1 $\beta$, IL-3, IL-5, IL-13 or IL-17A. The exposure concentrations of the cytokines were defined as approximately equal to the highest level observed in the PBMC supernatants (Fig. 2). The results indicated that the cytokines other than G-CSF and GM-CSF increased cell growth significantly in comparison to that of control cells $(\mathrm{P}<0.01)(\mathrm{OD} 450 \mathrm{~nm}$ : Control, $1.000 \pm 0.035$; G-CSF, $1.051 \pm 0.049, \mathrm{P}=0.021$; GM-CSF, $1.032 \pm 0.041, \mathrm{P}=0.516$; IL- $1 \alpha, 1.087 \pm 0.059, \mathrm{P}<0.0001$; IL-1 $\beta, 1.071 \pm 0.049, \mathrm{P}=0.0002$; 







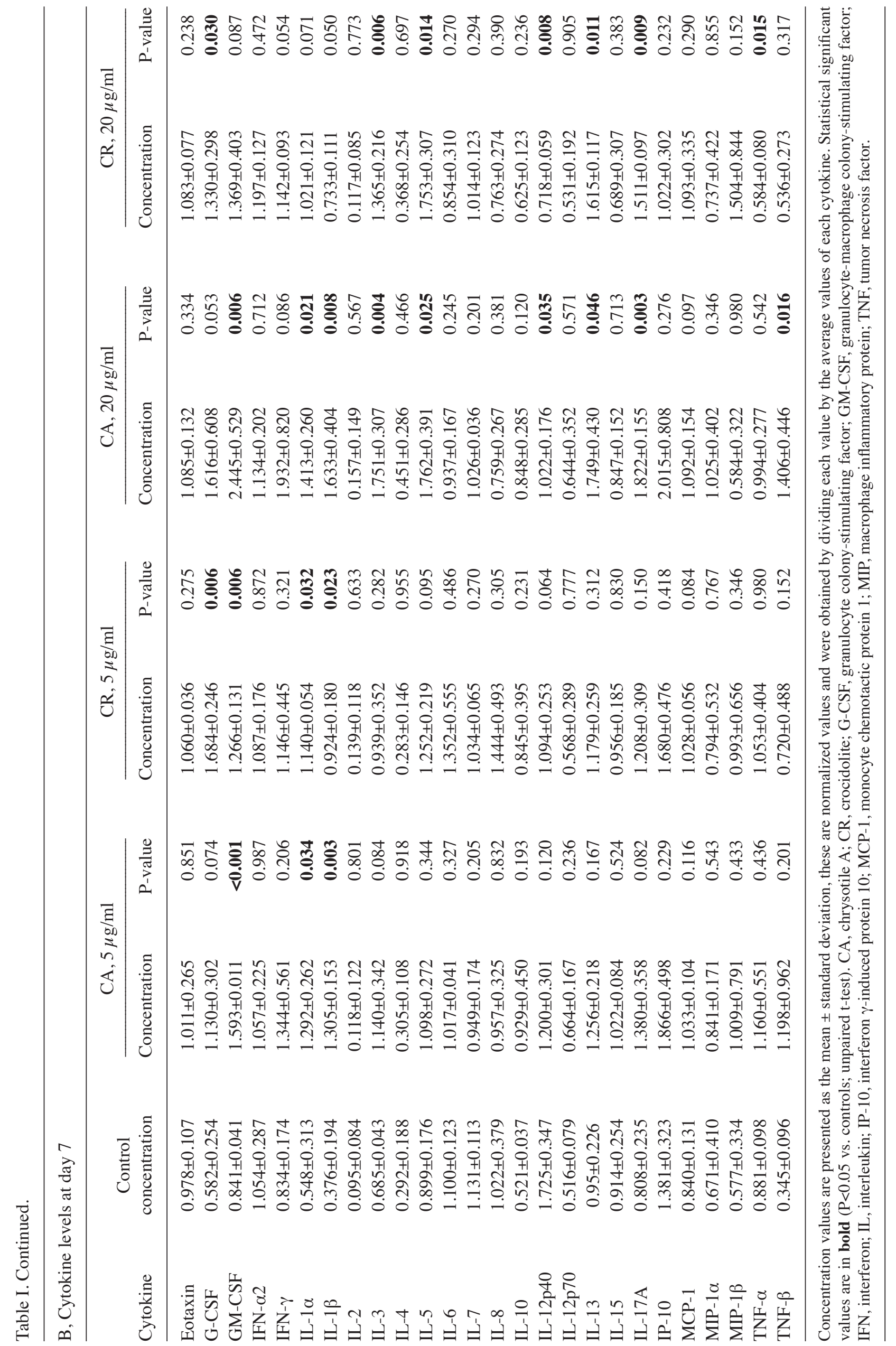



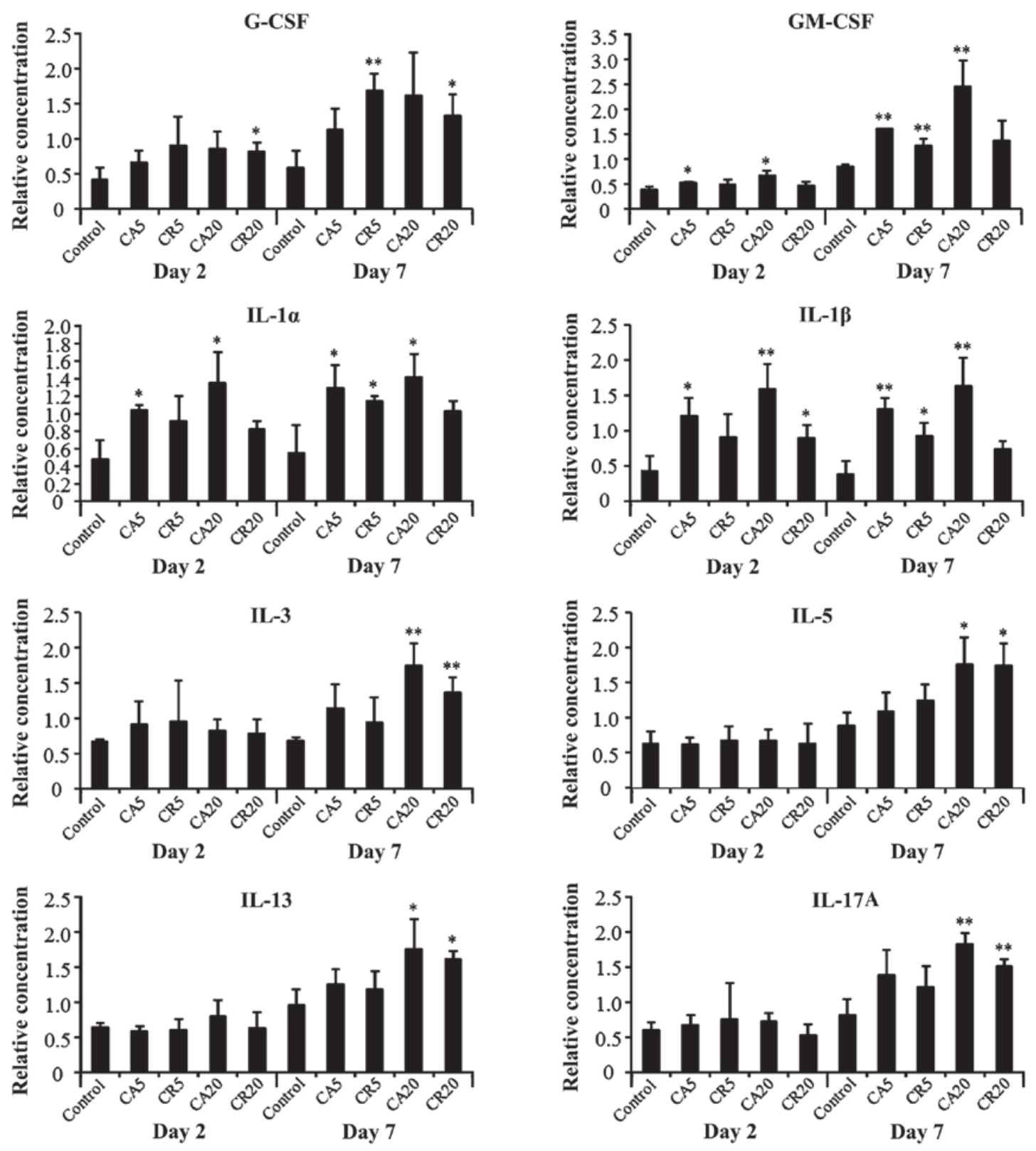

Figure 2. Increased production of cytokines by asbestos-exposed PBMCs upon T-cell stimulation. PBMCs were cultured with 5 or $20 \mu \mathrm{g} / \mathrm{ml}$ of CA or CR upon stimulation with antibodies against CD3 and CD28 for 2 or 7 days, and culture supernatants were harvested and assayed for cytokine levels using a Luminex system. Among the 26 cytokines assayed, the levels of 8 cytokines exhibited significant increases. All values were corrected as the ratio relative to the averages of all samples for each cytokine. Values are expressed as the mean \pm standard deviation. Statistical significance is expressed as ${ }^{*} \mathrm{P}<0.05$ or ${ }^{* *} \mathrm{P}<0.01$ vs. controls. PBMC, peripheral blood mononuclear cell; CA, chrysotile A; CR, crocidolite; CD, cluster of differentiation; CA5, $5 \mu \mathrm{g} / \mathrm{ml}$ CA; CR5, $5 \mu \mathrm{g} / \mathrm{ml}$ CR; CA20, 20 $\mu \mathrm{g} / \mathrm{ml}$ CA; CR20, $20 \mu \mathrm{g} / \mathrm{ml} \mathrm{CR}$; G-CSF, granulocyte-colony stimulating factor; GM-CSF, granulocyte-macrophage colony-stimulating factor; IL, interleukin.

IL-3, 1.115 $\pm 0.067, \mathrm{P}<0.0001 ;$ IL-5, $1.086 \pm 0.082, \mathrm{P}<0.0001$ IL-13, 1.106 $\pm 0.053, \mathrm{P}<0.0001 ;$ IL-17A, $1.116 \pm 0.062$, $\mathrm{P}<0.0001$ ), although the differences were not large (Fig. 3). Notably, when all cytokines were included the culture simultaneously, the growth of the MeT-5A cells did not differ from that of the control (OD450 nm, 1.027 $\pm 0.089 ; \mathrm{P}=0.803$ ). Subsequently, the potential additive effects of several selected cytokines on the growth of MeT-5A cells were examined. However, no increase in cell growth was observed in these cultures (OD450 nm: Control, 1.000 \pm 0.078 ; IL3/13/17, $0.942 \pm 0.054, \mathrm{P}=0.102 ; \mathrm{IL}-1 \alpha / 3 / 13 / 17 \mathrm{~A}, 0.954 \pm 0.058$, $\mathrm{P}=0.400 ; \mathrm{IL}-3 / 5 / 13 / 17 \mathrm{~A}, 0.948 \pm 0.052, \mathrm{P}=0.413)$. These results indicate that IL-1 $\alpha$, IL-1 $\beta$, IL-3, Il-5, Il-13 and IL-17A have the potential to augment the growth activity of mesothelial cells, although these effects are not strong and are altered in the presence of other cytokines.

\section{Discussion}

In the current study, PBMCs were exposed to asbestos under stimulation with anti-CD3 and anti-CD28 antibodies to drive T-cell activation in vitro (19). The results demonstrated that supernatants from PBMC cultures upon exposure to $20 \mu \mathrm{g} / \mathrm{ml}$ of asbestos for 7 days significantly enhanced the cell growth of MeT-5A, and exhibited markedly higher levels of IL-1 $\alpha$, IL-1 $\beta$, IL-3, IL-5, IL-13 and IL-17A. These cytokines are often reported as pro-inflammatory cytokines (22). In addition, these cytokines were confirmed to be able to enhance 
A

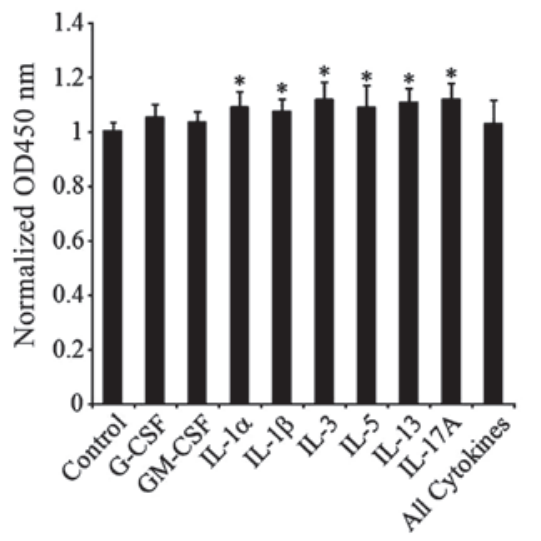

B

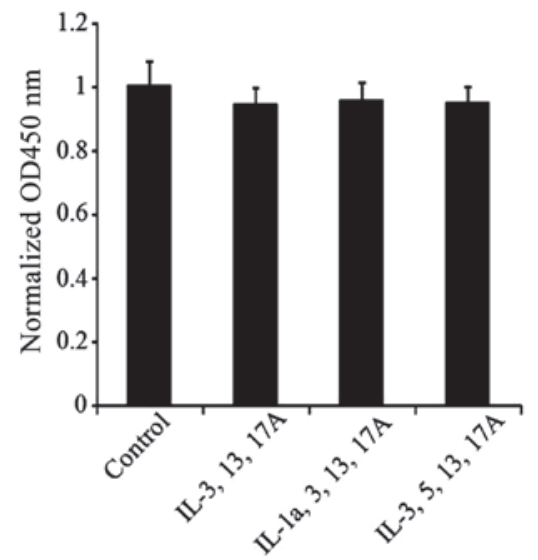

Figure 3. The effects of recombinant cytokines on cell growth of human mesothelial cells. MeT-5A cells were cultured with (A) G-CSF, GM-CSF, IL-1 $\alpha$, IL-1 $\beta$, IL-3, IL-5, IL-13 or IL-17A, and cell growth was evaluated using WST-1 assays. Some groups of cells were cultured with a mixture of all cytokines or (B) with various combinations of cytokines. Concentrations were selected according to the concentrations of cytokines in peripheral blood mononuclear cell cultures determined by the Luminex system. Values are expressed as the ratio relative to the control and as the mean \pm standard deviation. Statistical significance is expressed as " $\mathrm{P}<0.01$ vs. controls. G-CSF, granulocyte-colony stimulating factor; GM-CSF, granulocyte-macrophage colony-stimulating factor; IL, interleukin; OD450 nm, optical density at $450 \mathrm{~nm}$.

the proliferation of MeT-5A cells. Collectively, these results indicate that cytokines secreted by immune cells upon exposure to asbestos cause an increase in the growth activity of mesothelial cells, suggesting the possibility that pleural cells may be influenced by these cytokines in individuals exposed to asbestos.

It is often reported that chronic inflammation has the potential to contribute to carcinogenesis; however, this mechanism is complex $(23,24)$. Inhalation of asbestos also causes inflammatory responses that include production of free radicals and cytokines, as well as induction of cell death, which is thought to be important carcinogenesis resulting from asbestos exposure (25). One notable finding from the present study is the relationship between immune cells and mesothelial cells as mediated by IL- $1 \alpha$ and IL- $1 \beta$, which are representative types of inflammatory cytokines. IL-1 $\alpha$ and IL-1 $\beta$ have a biologically similar function and promote tumor angiogenesis, invasion and metastasis through activating nuclear factor- $\kappa \mathrm{B}$ (26). Alveolar macrophages collected from asbestosis patients exhibit increased levels of IL-1 $\beta$ (27). It is well known that asbestos can induce activation of caspase- 1 mediated by the NLRP3 inflammasome; IL-1 $\beta$ is produced by cleavage of the inactive pro-IL-1 $\beta$ precursor by caspase-1 $(28,29)$.

IL-5 was originally identified as a B-cell growth factor in mice. IL-5 stimulates B-cell proliferation and activation, and regulates eosinophil differentiation through Ras-mitogen-activated protein kinase (MAPK), phosphoinositide 3-kinase and Janus kinase-signal transducer and activator of transcription (JAK-STAT) pathways (30). IL-5 is critical in allergic diseases, such as asthma and rhinitis; however, little is known with regard to the effects of IL-5 on mesothelial cells. Several studies have reported that IL-5 is one of the cytokines that exhibits increased levels in asbestos-exposed murine bronchoalveolar lavage (BAL) fluid $(31,32)$. IL-5 is upregulated in invasive bladder cancer and stimulates the invasion of bladder cancer cell lines through the Ras-MAPK and JAK-STAT pathways, which are also important in MM (33).
IL-13 is secreted by activated T helper $\left(\mathrm{T}_{\mathrm{h}}\right)$ type 2 cells and shares numerous biological activities with IL-4 (34). Although there is insufficient data concerning the involvement of IL-13 in mesothelioma or asbestosis, increased IL-13 has been observed in a peritoneal mesothelial cell line exposed to asbestos, and lymphocytes co-cultured with asbestos-exposed human alveolar macrophages are reported to produce IL-13 (35,36). Takenouchi et al (37) reported that IL-13 receptor $\alpha 2$ (IL-13Ra2) was upregulated by treatment with the DNA methylation inhibitor 5-aza-2'-deoxycytidine and that the anti-IL-13Ra2 antibody exerted a tumor suppressive effect in mesothelioma cells. Silencing of IL-13Ra2 has also been demonstrated to decrease migration and invasion in colorectal cancer cells, while IL-13 has increased these events (38).

IL-17A is predominantly secreted by $T_{h} 17$ cells and is important in the development of autoimmune diseases, including rheumatoid arthritis and multiple sclerosis (39). Additionally, significant upregulation of IL-17A has been observed with acute alveolitis induced in experimental mouse silicosis (40). The suggested role of IL-17A in the development of cancer is controversial: Poor prognosis of colorectal cancer patients with high expression of $\mathrm{T}_{\mathrm{h}} 17$ has been suggested (41); however, a tumor suppressive effect has also been reported (42).

It has been reported that inhaled asbestos fibers relocate and accumulate in the lymph nodes from the lung via the lymphatic system $(43,44)$. Therefore, immunocompetent cells, including $\mathrm{T}$ cells, may be chronically exposed to asbestos. Numerous studies have investigated cytokines in peripheral blood, BAL fluid or the pleural effusion of asbestos-exposed workers, or in a murine model $(32,45,46)$. In the present study, PBMCs were directly exposed to asbestos and secreted cytokines were measured, before their effects on mesothelial cells were investigated.

Various studies of cancer immunology have identified subpopulations of $\mathrm{T}$ cells, in particular noting the balance of $T_{h} 2$ and $T_{h} 1$ cells systematically or in tumor sites (47-50). $T_{h} 1$ cytokines predominantly mediate cellular immunity, while $\mathrm{T}_{\mathrm{h}} 2$ cytokines mediate hormonal immunity; each type of cytokine 
can suppress the other type of cytokine, and the $T_{h} 1 / T_{h} 2$ balance is thus considered to be an important factor in various diseases. A disorder in this balance may lead to autoimmune diseases $(51,52)$. In cancer, $\mathrm{T}_{\mathrm{h}} 1$ cytokines support the activation of cytotoxic $\mathrm{T}$ cells that can promote apoptosis in cancer cells (47), and a predominance of $\mathrm{T}_{\mathrm{h}} 2$ may cause suppression of cancer immunity. The present study identified significant upregulation of IL-5 and IL-13, which are categorized as $\mathrm{T}_{\mathrm{h}} 2$ cytokines; by contrast, $\mathrm{T}_{\mathrm{h}} 1$ cytokines, such as IFN- $\gamma$, did not increase upon exposure to asbestos. Such a predominance of $\mathrm{T}_{\mathrm{h}} 2$ cytokines upon exposure to asbestos may promote cancer development in MM.

The current study demonstrated that secretory factors derived from PBMCs exposed to asbestos cause an increase in the growth of mesothelial cells. In fact, several cytokines were associated with increased cell growth. However, the increases observed with recombinant cytokines were smaller than those caused by PBMC supernatants upon exposure to asbestos. In addition, the combined administration of the cytokines did not induce an increase in cell growth. These findings highlighted two issues that must be resolved. The first issue is to identify the optimal combination of cytokines and their adequate concentrations for the growth of mesothelial cells. Although a number of experiments were conducted to explore these aspects, these properties were not identified in the present study. The second issue is to examine other secretory factors, including cytokines not assayed in the present study, and non-cytokine molecules, such as lipid mediators, hormones and catecholamines. Future study of these issues will further clarify the relationship between mesothelial cells and the secretory factors derived from immune cells exposed to asbestos, and will contribute to a greater understanding of the pathogenesis of mesothelioma.

In conclusion, the results of the present study indicate that chronic exposure of immunocompetent cells to asbestos may stimulate the secretion of pro-inflammatory cytokines and $\mathrm{T}_{\mathrm{h}} 2$ cytokines. These cytokines increase the growth activity of mesothelial cells. The effects of cytokines produced by immune cells upon exposure to asbestos may contribute to the development of $\mathrm{MM}$ in individuals exposed to asbestos, in addition to the direct effect of asbestos on mesothelial cells (3). Further studies are required to evaluate the association between immunological disturbances caused by asbestos and the pathogenesis of MM.

\section{Acknowledgements}

This study was supported in part by Japan Society for the Promotion of Science Kakenhi Grants (grant nos. 20390178 and 24590770), Kawasaki Medical School Project Grants (grant no. 23P-3), Okayama-Ken organization (Okayama, Japan; grant nos. 2010B4, 2011B6 and 2012B3), and Strategic Research Foundation Grant-aided Project for Private Universities from the Ministry of Education, Culture, Sport, Science and Technology. The authors would like to thank Ms. Tamayo Hatayama and Ms. Shoko Yamamoto (Department of Hygiene, Kawasaki Medical School) for their technical help.

\section{References}

1. Becklake MR, Bagatin E and Neder JA: Asbestos-related diseases of the lungs and pleura: Uses, trends and management over the last century. Int J Tuberc Lung Dis 11: 356-369, 2007.
2. Straif K, Benbrahim-Tallaa L, Baan R, Grosse Y, Secretan B, El Ghissassi F, Bouvard V, Guha N, Freeman C, Galichet $\mathrm{L}$ and Cogliano V; WHO International Agency for Research on Cancer Monograph Working Group: A review of human carcinogen - Part C: Metals, arsenic, dusts, and fibres. Lancet Oncol 10: 453-454, 2009.

3. Upadhyay D and Kamp DW: Asbestos-induced pulmonary toxicity: Role of DNA damage and apoptosis. Exp Biol Med (Maywood) 228: 650-659, 2003.

4. Lanphear BP and Buncher CR: Latent period for malignant mesothelioma of occupational origin. J Occup Med 34: 718-721, 1992.

5. Miura Y, Nishimura $\mathrm{Y}$, Katsuyama $\mathrm{H}$, Maeda M, Hayashi $\mathrm{H}$, Dong M, Hyodoh F, Tomita M, Matsuo Y, Uesaka A, et al: Involvement of IL-10 and $\mathrm{Bcl}-2$ in resistance against an asbestos-induced apoptosis of $\mathrm{T}$ cells. Apoptosis 11: 1825-1835, 2006

6. Murakami S, Nishimura Y, Maeda M, Kumagai N, Hayashi H, Chen Y, Kusaka M, Kishimoto T and Otsuki T: Cytokine alteration and speculated immunological pathophysiology in silicosis and asbestos-related diseases. Environ Health Prev Med 14: 216-222, 2009.

7. Otsuki T, Maeda M, Murakami S, Hayashi H, Miura Y, Kusaka M, Nakano T, Fukuoka K, Kishimoto T, Hyodoh F, et al: Immunological effects of silica and asbestos. Cell Mol Immunol 4: 261-268, 2007.

8. Kumagai-Takei N, Nishimura Y, Maeda M, Hayashi H, Matsuzaki H, Lee S, Hiratsuka J and Otsuki T: Effect of asbestos exposure on differentiation of cytotoxic T lymphocytes in mixed lymphocyte reaction of human peripheral blood mononuclear cells. Am J Respir Cell Mol Biol 49: 28-36, 2013.

9. Nishimura Y, Kumagai-Takei N, Matsuzaki H, Lee S, Maeda M, Kishimoto T, Fukuoka K, Nakano T and Otsuki T: Functional alteration of natural killer cells and cytotoxic $\mathrm{T}$ lymphocytes upon asbestos exposure and in malignant mesothelioma patients. BioMed Res Int 2015: 238431, 2015.

10. Nishimura Y, Maeda M, Kumagai-Takei N, Lee S, Matsuzaki H, Wada Y, Nishiike-Wada T, Iguchi H and Otsuki T: Altered functions of alveolar macrophages and NK cells involved in asbestos-related diseases. Environ Health Prev Med 18: 198-204, 2013.

11. Nishimura Y, Maeda M, Kumagai-Takei N, Matsuzaki H, Lee S, Fukuoka K, Nakano T, Kishimoto T and Otsuki T: Effect of asbestos on anti-tumor immunity and immunological alteration in patients with mesothelioma. In: Malignant Mesothelioma. Belli C and Anand S (eds). InTech, Rijeka, pp31-48, 2012.

12. Miller J and Shukla A: The role of inflammation in development and therapy of malignant mesothelioma. Am Med J 3: 240-248, 2012.

13. Yang H, Bocchetta M, Kroczynska B, Elmishad AG, Chen Y, Liu Z, Bubici C, Mossman BT, Pass HI, Testa JR, et al: TNF-alpha inhibits asbestos-induced cytotoxicity via a NF-kappaB-dependent pathway, a possible mechanism for asbestos-induced oncogenesis. Proc Natl Acad Sci USA 103: 10397-10402, 2006.

14. Mossman BT, Shukla A, Heintz NH, Verschraegen CF, Thomas A and Hassan R: New insights into understanding the mechanisms, pathogenesis, and management of malignant mesotheliomas. Am J Pathol 182: 1065-1077, 2013.

15. Hillegass JM, Shukla A, Lathrop SA, MacPherson MB, Beuschel SL, Butnor KJ, Testa JR, Pass HI, Carbone M, Steele C and Mossman BT: Inflammation precedes the development of human malignant mesotheliomas in a SCID mouse xenograft model. Ann NY Acad Sci 1203: 7-14, 2010.

16. Kasuga I, Ishizuka S, Minemura K, Utsumi K, Serizawa H and Ohyashiki K: Malignant pleural mesothelioma produces functional granulocyte-colony stimulating factor. Chest 119: 981-983, 2001.

17. Maeda M, Miura Y, Nishimura Y, Murakami S, Hayashi H, Kumagai N, Hatayama $T$, Katoh M, Miyahara N, Yamamoto S, et al: Immunological changes in mesothelioma patients and their experimental detection. Clin Med Circ Respirat Pulm Med 2: 11-17, 2008.

18. Nakano T, Chahinian AP, Shinjo M, Tonomura A, Miyake M, Togawa N, Ninomiya K and Higashino K: Interleukin 6 and its relationship to clinical parameters in patients with malignant pleural mesothelioma. Br J Cancer 77: 907-912, 1998.

19. Riddell SR and Greenberg PD: The use of anti-CD3 and anti-CD28 monoclonal antibodies to clone and expand human antigen-specific T cells. J Immunol Methods 128: 189-201, 1990. 
20. Nishimura Y, Miura Y, Maeda M, Kumagai N, Murakami S, Hayashi H, Fukuoka K, Nakano T and Otsuki T: Impairment in cytotoxicity and expression of $\mathrm{NK}$ cell-activating receptors on human NK cells following exposure to asbestos fibers. Int $\mathbf{J}$ Immunopathol Pharmacol 22: 579-590, 2009.

21. Otsuki T, Hata H, Harada N, Matsuzaki H, Yata K, Wada H, Yawata Y, Ueki A and Yamada O: Cellular biological differences between human myeloma cell lines KMS-12-PE and KMS-12-BM established from a single patient. Int J Hematol 72: 216-222, 2000

22. Dinarello CA: Proinflammatory cytokines. Chest 118: 503-508, 2000.

23. Coussens LM and Werb Z: Inflammation and cancer. Nature 420: 860-867, 2002

24. Rakoff-Nahoum S: Why cancer and inflammation? Yale J Biol Med 79: 123-130, 2006.

25. Hamilton RF Jr, Thakur SA and Holian A: Silica binding and toxicity in alveolar macrophages. Free Radic Biol Med 44: 1246-1258, 2008.

26. Multhoff G, Molls M and Radons J: Chronic inflammation in cancer development. Front Immunol 2: 98, 2012.

27. Zhang Y, Lee TC, Guillemin B, Yu MC and Rom WN: Enhanced IL-1 beta and tumor necrosis factor-alpha release and messenger RNA expression in macrophages from idiopathic pulmonary fibrosis or after asbestos exposure. J Immunol 150: 4188-4196, 1993

28. Dostert C, Pétrilli V, Van Bruggen R, Steele C, Mossman BT and Tschopp J: Innate immune activation through Nalp3 inflammasome sensing of asbestos and silica. Science 320: 674-677, 2008.

29. Franchi L, Eigenbrod T, Muñoz-Planillo R and Nuñez G: The inflammasome: A caspase-1-activation platform that regulates immune responses and disease pathogenesis. Nat Immunol 10 241-247, 2009.

30. Alam R, Pazdrak K, Stafford S and Forsythe P: The lnterleukin-5/receptor interaction activates Lyn and Jak2 tyrosine kinases and propagates signals via the Ras-Raf-1-MAP kinase and the Jak-STAT pathways in eosinophils. Int Arch Allergy Immunol 107: 226-227, 1995.

31. Sabo-Attwood T, Ramos-Nino M, Bond J, Butnor KJ, Heintz N, Gruber AD, Steele C, Taatjes DJ, Vacek P and Mossman BT: Gene expression profiles reveal increased mClca3 (Gob5) expression and mucin production in a murine model of asbestos-induced fibrogenesis. Am J Pathol 167: 1243-1256, 2005.

32. Sabo-Attwood T, Ramos-Nino ME, Eugenia-Ariza M, Macpherson MB, Butnor KJ, Vacek PC, McGee SP, Clark JC, Steele C and Mossman BT: Osteopontin modulates inflammation, mucin production, and gene expression signatures after inhalation of asbestos in a murine model of fibrosis. Am J Pathol 178: 1975-1985, 2011.

33. Lee SJ, Lee EJ, Kim SK, Jeong P, Cho YH, Yun SJ, Kim S, Kim GY, Choi YH, Cha EJ, et al: Identification of pro-inflammatory cytokines associated with muscle invasive bladder cancer; The roles of IL-5, IL-20, and IL-28A. PLoS One 7: e40267, 2012.

34. Zurawski G and de Vries JE: Interleukin 13, an interleukin 4-like cytokine that acts on monocytes and B cells, but not on $\mathrm{T}$ cells Immunol Today 15: 19-26, 1994.

35. Hamilton RF Jr, Holian A and Morandi MT: A comparison of asbestos and urban particulate matter in the in vitro modification of human alveolar macrophage antigen-presenting cell function. Exp Lung Res 30: 147-162, 2004.

36. Hillegass JM, Shukla A, MacPherson MB, Bond JP, Steele C and Mossman BT: Utilization of gene profiling and proteomics to determine mineral pathogenicity in a human mesothelial cell line (LP9/TERT-1). J Toxicol Environ Health A 73: 423-436, 2010.
37. Takenouchi M, Hirai S, Sakuragi N, Yagita H, Hamada H and Kato K: Epigenetic modulation enhances the therapeutic effect of anti-IL-13R(alpha)2 antibody in human mesothelioma xenografts. Clin Cancer Res 17: 2819-2829, 2011.

38. Barderas R, Bartolomé RA, Fernandez-Aceñero MJ, Torres S and Casal JI: High expression of IL-13 receptor $\alpha 2$ in colorectal cancer is associated with invasion, liver metastasis and poor prognosis. Cancer Res 72: 2780-2790, 2012.

39. Kolls JK and Lindén A: Interleukin-17 family members and inflammation. Immunity 21: 467-476, 2004.

40. Lo Re S, Dumoutier L, Couillin I, Van Vyve C, Yakoub Y, Uwambayinema F, Marien B, van den Brûle S, Van Snick J, Uyttenhove C, et al: IL-17A-Producing gammadelta T and Th17 lymphocytes mediate lung inflammation but not fibrosis in experimental silicosis. J Immunol 184: 6367-6377, 2010.

41. Tosolini M, Kirilovsky A, Mlecnik B, Fredriksen T, Mauger S, Bindea G, Berger A, Bruneval P, Fridman WH, Pagès F and Galon J: Clinical impact of different classes of infiltrating T cytotoxic and helper cells (Th1, Th2, Treg, Th17) in patients with colorectal cancer. Cancer Res 71: 1263-1271, 2011.

42. Kryczek I, Wei S, Szeliga W, Vatan L and Zou W: Endogenous IL-17 contributes to reduced tumor growth and metastasis. Blood 114: 357-359, 2009.

43. Dodson RF, Williams MG Jr, Corn CJ, Brollo A and Bianchi C: A comparison of asbestos burden in lung parenchyma, lymph nodes, and plaques. Ann N Y Acad Sci 643: 53-60, 1991.

44. Miserocchi G, Sancini G, Mantegazza F and Chiappino G: Translocation pathways for inhaled asbestos fibers. Environ Health 7: 4, 2008.

45. Lemaire I, Beaudoin H and Dubois C: Cytokine regulation of lung fibroblast proliferation. Pulmonary and systemic changes in asbestos-induced pulmonary fibrosis. Am Rev Respir Dis 134: 653-658, 1986

46. Geist LJ, Powers LS, Monick MM and Hunninghake GW: Asbestos stimulation triggers differential cytokine release from human monocytes and alveolar macrophages. Exp Lung Res 26: 41-56, 2000.

47. Shurin MR, Lu L, Kalinski P, Stewart-Akers AM and Lotze MT: Th1/Th2 balance in cancer, transplantation and pregnancy. Springer Semin Immunopathol 21: 339-359, 1999.

48. Lauerova L, Dusek L, Simickova M, Kocák I, Vagundová M, Zaloudík J and Kovarík J: Malignant melanoma associates with Th1/Th2 imbalance that coincides with disease progression and immunotherapy response. Neoplasma 49: 159-166, 2002.

49. Pellegrini P, Berghella AM, Del Beato T, Cicia S, Adorno D and Casciani CU: Disregulation in $\mathrm{TH} 1$ and $\mathrm{TH} 2$ subsets of $\mathrm{CD} 4^{+}$ $\mathrm{T}$ cells in peripheral blood of colorectal cancer patients and involvement in cancer establishment and progression. Cancer Immunol Immunother 42: 1-8, 1996

50. Sato M, Goto S, Kaneko R, Ito M, Sato S and Takeuchi S: Impaired production of Th1 cytokines and increased frequency of Th2 subsets in PBMC from advanced cancer patients. Anticancer Res 18 (5D): 3951-3955, 1998.

51. Schulze-Koops $H$ and Kalden JR: The balance of Th1/Th2 cytokines in rheumatoid arthritis. Best Pract Res Clin Rheumatol 15: 677-691, 2001.

52. Kidd P: Th1/Th2 balance: The hypothesis, its limitations, and implications for health and disease. Altern Med Rev 8: 223-246, 2003. 